\title{
Antibiotic prescribing and expenditures in outpatient adults in Greece, 2010 to 2013: evidence from real-world practice
}

G Kourlaba ${ }^{1}$, E Gkrania-Klotsas ${ }^{2}$, E Kourkouni ${ }^{1}$, G Mavrogeorgos ${ }^{1}$, TE Zaoutis ${ }^{13}$

1. Collaborative Center for Clinical Epidemiology and Outcomes Research (CLEO), Athens, Greece

2. Medical Research Council Epidemiology Unit, Department of Infectious Diseases and the Clinical School, University of Cambridge, Cambridge, United Kingdom

3. Division of Infectious Diseases, Children's Hospital of Philadelphia, UPENN School of Medicine, Philadelphia, United States

Correspondence: Georgia Kourlaba (kurlaba@gmail.com)

Citation style for this article:

Kourlaba G, Gkrania-Klotsas E, Kourkouni E, Mavrogeorgos G, Zaoutis TE. Antibiotic prescribing and expenditures in outpatient adults in Greece, 2010 to 2013: evidence from real-world practice. Euro Surveill. 2016;21(26):pii=30266. DOI: http://dx.doi.org/10.2807/1560-7917.ES.2016.21.26.30266

We provide a representative analysis of antibiotic prescribing, identify factors associated with broadspectrum antibiotic prescribing and assess the costs associated with antibiotic use in adult outpatients in Greece. Outpatient antibiotic prescriptions for patientsolder than 19 years between 2010 and 2013 in Greece were extracted from the IMS Health Xponent database. Prescribing rate and total cost for prescribed antibiotics were calculated. Multivariate logistic regression was used to identify factors related to broad-spectrum antibiotic prescribing. More than 20 million antibiotics were prescribed during the study period, an annual rate of 768 prescribed antibiotics per 1,000 adults. Overall, $33.5 \%$ of antibiotics were prescribed for acute respiratory tract infections (ARTIs) for which antibiotics are often not indicated. Macrolides (29.9\%), cephalosporins (26.9\%) and fluoroquinolones $(21.0 \%)$ were the most commonly prescribed antibiotic classes. The majority (89.0\%) of antibiotics were broad-spectrum. Antibiotic expenditures were approximately EUR 185 million during the study period. Factors associated with broad-spectrum prescribing included older patient age, specialty pulmonologists or otorhinolaryngologists, training in eastern Europe, diagnosis of ARTI, acute diagnosis, and first episode of disease. Broad-spectrum antibiotic prescribing for ARTIs is common in adult Greek outpatients and frequently inappropriate. These data indicate the need for initiatives aiming to control antibiotic prescribing.

\section{Introduction}

Antibiotics are among the most frequently prescribed medications in adult outpatients in European countries such as Greece [1]. There is evidence that a number of antibiotic prescriptions are dispensed for viral infections, for which antibiotics provide no benefit [2]. Such prescriptions indicate an overuse of antibiotics, a common and alarming problem for many countries, potentially resulting in redundant drug spending, increased risks of adverse effects and development of antimicrobial resistance [3-5]. The latter is a rapidly growing global health problem [6-8].

In addition, over the last decades, the use of broadspectrum antibiotics has increased dramatically, contributing to further antibiotic resistance [9-11]. There are instances where antibiotics may be indicated, but instead of prescribing narrow-spectrum antibiotics, broad-spectrum antibiotics are inappropriately preferred [12].

Antibiotic resistance and increased healthcare costs are thought to be a considerable problem in Greece, which has one of the highest rates of antibiotic consumption and resistance among European countries [13,14]. During the last few years, Greece has experienced a significant financial crisis, resulting in healthcare budgetary constraints. Hence, avoiding unnecessary costs should be a top priority for policymakers. A thorough understanding of antibiotic prescribing patterns can help policy makers identify areas where potentially unnecessary costs can be avoided. Although data on antibiotic prescribing patterns are available for several European countries [15-22], such data are limited for Greece [13].

The aim of this study was to analyse antibiotic prescribing in adult outpatients and to identify factors associated with broad-spectrum antibiotic prescribing in Greece. The secondary objective was to assess the overall and class-specific antibiotic costs in Greece. 


\section{FIGURE 1}

Trend of prescribed antibiotics per 1,000 persons per six months, Greece, July 2010-June 2013

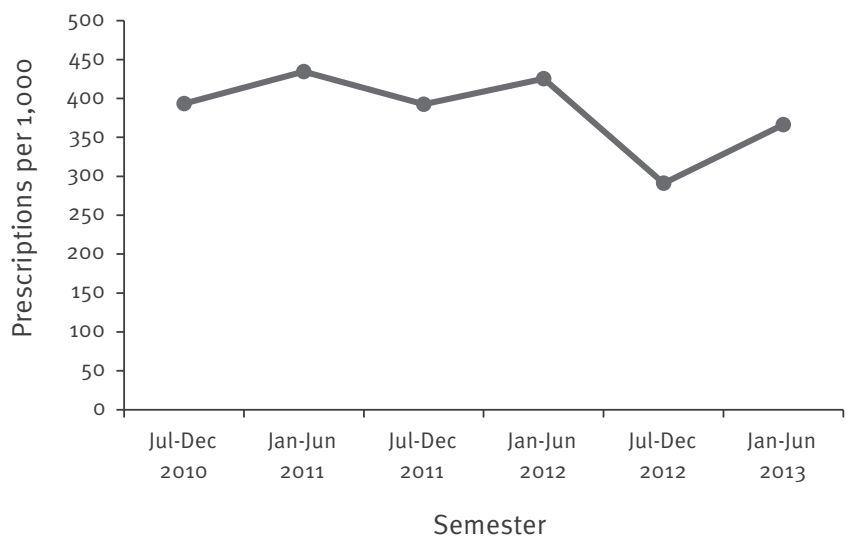

\section{Methods}

\section{Data source and design}

In order to obtain data for the analysis we used the Intercontinental Marketing Services (IMS) Health Xponent (XPO) Greece database. This database contains longitudinal representative data of prescribing activity in the community, on the basis of prescriptions given by a random cluster sample, by specialty and region, of 625 physicians ( $2.5 \%$ of all doctors in the outpatient setting in Greece). Physicians, systematically exchanged during the study period, filled in a form for every patient contacted, regardless of contact type (i.e. personal visit or telephone) for seven consecutive days, including the weekend. IMS data directly link antibiotic prescriptions to the clinical indication (ICD-9 codes) and provide diagnosis-related characteristics such as recurrence, the existence of co-diagnoses and the type of diagnosis (i.e. acute or chronic). Patient characteristics such as age, sex and type of insurance were also obtained from the database in addition to physician characteristics including specialty, training location, age and sex. We extracted data for all prescriptions given to patients older than 20 years between July 2010 and June 2013.

Consultations in Greece are mainly performed via private physicians. Antibiotic prescribing data are presented by specialty of the prescriber: general practitioners (GPs), the main antibiotic prescribers for adults, gynaecologists, pulmonologists, urologists, otorhinolaryngologists and all other specialties (cardiologists, endocrinologists, gastroenterologists, neurologists, orthopaedists, dermatologists and rheumatologists).

\section{Antibiotic classification and duration of therapy}

Antibiotics were categorised in two groups. Narrowspectrum antibiotics included narrow-spectrum penicillins (pivmecillinam, penicillin, amoxicillin), first

\section{FIGURE 2}

Most frequently prescribed antibiotics by clinical diagnosis, Greece, July 2010-June 2013
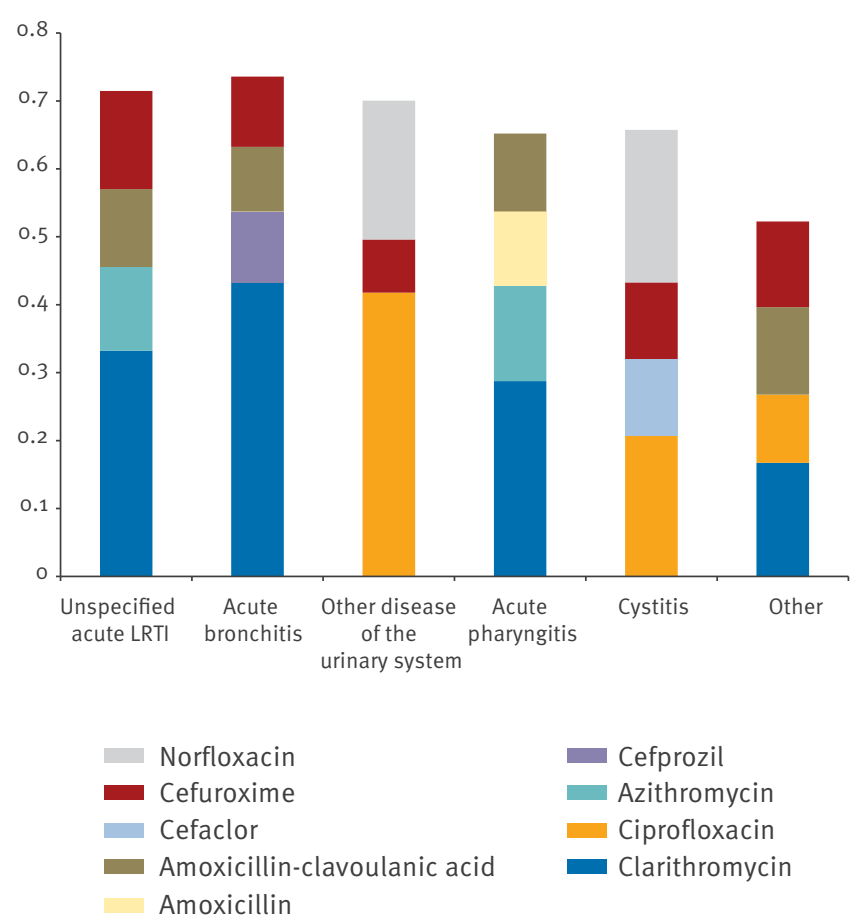

LRTI: lower respiratory tract infection.

generation cephalosporins, tetracyclines and sulfonamides; broad-spectrum antibiotics included broadspectrum penicillins (amoxicillin/clavulanic acid), macrolides, second and third generation cephalosporins and quinolones. This classification has been used in previously published research [12]. Moreover, the duration of therapy was calculated using the total prescribed dose (number of packs) with the daily dose and dose frequency as recommended by physicians.

\section{Diagnostic categories}

Clinical diagnoses were provided by physicians (tonsillitis, sinusitis, etc.). If the physician could not decide on a specific diagnosis, they had to mention the basic symptoms (chest pain, headache, etc.). The 10 most common clinical diagnoses for which antibiotics were prescribed were used in the analysis, whereas the rest of diagnoses were grouped in the category 'other'. Moreover, to estimate the inappropriate prescription of antibiotics, acute respiratory tract infections (ARTIs) for which antibiotics are rarely or not indicated were identified based on the definition used in a previously published survey [12], so that our results are directly comparable to this previous study. To be more specific, abnormal sputum, allergy, asthma, bronchitis (acute and not otherwise specified), chronic bronchitis, chronic sinusitis, cough, dyspnoea, haemoptysis, influenza, laryngitis/tracheitis, nasopharyngitis, stridor, unspecified ARTIs and viral pneumonia 
TABLE 1

Antibiotic prescribing rates in adult outpatients, Greece, July 2010-June 2013

\begin{tabular}{|c|c|c|c|c|}
\hline Age (years) & $\begin{array}{l}\text { Number of prescribed antibiotics } \\
\text { (millions) }\end{array}$ & Greek population $2011^{a}$ & $\begin{array}{c}\text { Prescribed antibiotics } \\
\text { per 1,000 persons per year } \\
(95 \% \mathrm{Cl})\end{array}$ & $\begin{array}{c}\text { Treatment duration } \\
\text { mean (SD) }\end{array}$ \\
\hline $20-29$ & 3.3448 & $1,350,868$ & $825(824.51-826.28)$ & $9.14(4.87)$ \\
\hline $30-39$ & 4.0870 & $1,635,304$ & $833(832.47-834.09)$ & $9.08(4.26)$ \\
\hline $40-49$ & 3.6150 & $1,581,095$ & $762(761.34-762.92)$ & $9.18(4.12)$ \\
\hline $50-59$ & 2.9617 & $1,391,854$ & $709(708.56-710.17)$ & $9.16(4.05)$ \\
\hline$\geq 60$ & 6.0165 & $2,734,621$ & $733(732.85-734.02)$ & $9.01(4.04)$ \\
\hline Total & 20.025 & $8,693,742$ & $768(767.45-768.13)$ & $9.09(4.25)$ \\
\hline
\end{tabular}

$\mathrm{Cl}$ : confidence interval.

SD: standard deviation

${ }^{a}$ Based on census 2011 [30].

were considered as diagnoses for which antibiotics are rarely or not indicated.

\section{Costs}

The total antibiotic expenditures for adult outpatients from the perspective of the National Health Insurance were calculated based on the total dose (number of packs) of each antibiotic as well as the corresponding reimbursed drug prices. These prices were obtained from the reimbursed drug list published by the Ministry of Health, reduced by the patient's co-payment (25\%). Costs data reflect the year 2013 .

\section{Statistical analysis}

All collected variables were analysed descriptively. Nominal variables were analysed using frequencies and percentages. Treatment duration was presented as median and interquartile range (IQR), since it was not normally distributed. In order to calculate the antibiotic prescribing rates, we used the number of prescriptions and 2011 census denominators from the Hellenic Statistical Authority [30].

Chi-squared tests of independence were performed in order to evaluate the independence between broadand narrow-spectrum antibiotic prescription and patient, physician and diagnosis characteristics. In addition, we performed simple and multivariate logistic regressions to identify factors associated with broad-spectrum antibiotic prescribing. In the multivariate logistic regression model, we entered the factors found to be significantly associated with broad-spectrum antibiotic prescribing at a univariate level. These results are presented as odds ratios (OR) with 95\% confidence intervals $(95 \% \mathrm{Cl})$. The significance level was 0.05 (two-sided). Bonferroni correction was applied to adjust for multiple comparisons. Time series analysis was conducted to assess the antibiotic prescription trend over time. Finally, non-parametric statistic tests (i.e. Mann-Whitney and Kruskal-Wallis) were used to assess the association between selected patient, physician and diagnosis characteristics and treatment duration. The analysis was performed using SPSS 20.

\section{Results}

Antibiotic prescribing patterns

During the study period, an estimated 20 million antibiotic regimens were prescribed in Greece to adult outpatients, resulting in an annual rate of 768 prescribed antibiotics per 1,000 adults (95\% Cl: 767.45-768.13), with a median duration therapy of eight days (IQR: 6.010.5) (Table 1). Prescribing rates were higher among adultsyounger than 40 years (830 prescriptions/1,000 adults; 95\% Cl: 829.12-830.31) compared with adults 40 years and older (736 prescriptions/1,000 adults; 95\% Cl: 735.11-736.22), while no statistically significant difference was detected in treatment duration across the age groups $(p=0.330)$. Details on prescribing rates stratified by 10 -year age bands are presented in Table 1. Time trend analysis suggested a slight decline in antibiotic prescribing rate during the last two semesters of the study period, although no statistically significant trend was detected $(p=0.742)$ (Figure 1$)$.

The majority of prescribed antibiotics (89.0\%) were broad-spectrum; no difference was detected in treatment duration between broad- and narrow-spectrum antibiotics. The most frequently prescribed antibiotics were macrolides (29.9\%), second and third generation cephalosporins (26.9\%), fluoroquinolones (21.0\%), and penicillins $(15.4 \%$, a quarter of which were narrow spectrum). Clarithromycin (19.8\%), cefuroxime (11.8\%), ciprofloxacin (11.6\%), amoxicillin/clavulanic acid (10.8\%) and cefprozil $(7.6 \%)$ made up $61.6 \%$ of all prescribed antibiotics. Trimethoprim/sulfamethoxazole was rarely prescribed, accounting for $1.6 \%$ of total prescriptions (Table 2). With respect to treatment duration, it was found that the duration of macrolide therapy was significantly longer than cephalosporin therapy (median duration: 10.5 days vs 7.0 days). Clarithromycin and ciprofloxacin were the antibiotics prescribed with the longest duration (median: 10.5 days and 10.0 days, 
TABLE 2

Antibiotic prescribing patterns and expenditures in adult outpatients, Greece, July 2010-June 2013

\begin{tabular}{|c|c|c|c|c|c|}
\hline & $\begin{array}{c}\text { Number of } \\
\text { prescribed } \\
\text { antibiotics }\left(\times 10^{6}\right)\end{array}$ & $\begin{array}{l}\text { Proportion of } \\
\text { prescribed } \\
\text { antibiotics }\end{array}$ & $\begin{array}{l}\text { Expenditures } \\
\text { (in million EUR) }\end{array}$ & $\begin{array}{l}\text { Proportion of total } \\
\text { expenditures }\end{array}$ & $\begin{array}{c}\text { Treatment } \\
\text { duration } \\
\text { median (IQR) }\end{array}$ \\
\hline Total & 20.025 & & 184.6 & & $8(6-10.5)$ \\
\hline \multicolumn{6}{|l|}{ Antibiotic class } \\
\hline Macrolides & 5.9833 & $29.9 \%$ & 60.0 & $32.5 \%$ & $10.5 \underset{a, b, c}{(7-10.5)}$ \\
\hline Cephalosporins & 5.3781 & $26.9 \%$ & 53.6 & $29.0 \%$ & $7(6-12)^{a}$ \\
\hline Fluoroquinolones & 4.1991 & $21.0 \%$ & 58.2 & $31.5 \%$ & $10(7-10)^{a, b, c}$ \\
\hline Penicillins & 3.0761 & $15.4 \%$ & 6.1 & $3.3 \%$ & $8(5-8)$ \\
\hline Tetracyclines & 1.0153 & $5.1 \%$ & 3.4 & $1.8 \%$ & $8(8-12)^{a, c, c d}$ \\
\hline Trimethoprim/sulfamethoxazole & 0.3144 & $1.6 \%$ & 1.0 & $0.5 \%$ & $10(5-10)^{a}$ \\
\hline $\begin{array}{l}\text { Other beta-lactams excluding penicillins } \\
\text { and cephalosporins }\end{array}$ & 0.0591 & $0.3 \%$ & 2.4 & $1.3 \%$ & $10(5-10)$ \\
\hline \multicolumn{6}{|l|}{ Antibiotic $^{\mathrm{m}}$} \\
\hline Clarithromycin & 3.9661 & $19.8 \%$ & $45 \cdot 3$ & $24.5 \%$ & $\begin{array}{l}10.5(10.5- \\
10.5)^{\mathrm{e}^{-}}\end{array}$ \\
\hline Cefuroxime & 2.3724 & 11.9 & 21.7 & $11.7 \%$ & $7(7-14)^{f}$ \\
\hline Ciprofloxacin & 2.3312 & $11.6 \%$ & 28.1 & $15.2 \%$ & $10(10-10)$ \\
\hline Amoxicillin/clavulanic acid & 2.1681 & $10.8 \%$ & 5.1 & $2.8 \%$ & $8(4-8)^{g}$ \\
\hline Cefprozil & 1.5234 & $7.6 \%$ & 14.7 & $8.0 \%$ & $6(6-12)^{f}$ \\
\hline Azithromycin & 1.4300 & $7.1 \%$ & 10.8 & $5.9 \%$ & $6(4 \cdot 5-8)^{\mathrm{h}}$ \\
\hline Cefaclor & 1.1882 & $5.9 \%$ & 10.9 & $5.9 \%$ & $8(4-8) g$ \\
\hline \multicolumn{6}{|l|}{ Broad vs narrow spectrum } \\
\hline Narrow spectrum & 2.1975 & $11.0 \%$ & 5.1 & $2.7 \%$ & $8(6-12)$ \\
\hline Broad spectrum & 17.8275 & $89.0 \%$ & 179.6 & $97.3 \%$ & $8(7-10.5)$ \\
\hline \multicolumn{6}{|l|}{ Diagnosis } \\
\hline Unspecified acute LRTI & 2.4491 & $12.2 \%$ & 23.8 & $12.9 \%$ & $8(7-10.5)^{i}$ \\
\hline Acute bronchitis & 2.3552 & $11.8 \%$ & 22.4 & $12.1 \%$ & $10(7-10.5)^{i}$ \\
\hline $\begin{array}{l}\text { Other disease of urinary system than } \\
\text { cystitis }\end{array}$ & 2.2742 & $11.4 \%$ & 23.2 & $12.5 \%$ & $10(7-12)$ \\
\hline Acute pharyngitis & 0.8450 & $4.2 \%$ & 5.6 & $3.1 \%$ & $7(6-10.5)^{i}$ \\
\hline Cystitis & 0.8250 & $4.1 \%$ & 6.9 & $3.7 \%$ & $7(6-10)^{k}$ \\
\hline Acute sinusitis & 0.7881 & $3.9 \%$ & 9.1 & $4.9 \%$ & $10(7-10.7)$ \\
\hline Acute tonsillitis & 0.7420 & $3.7 \%$ & 5.9 & $3.2 \%$ & $8(7-10.5)$ \\
\hline $\begin{array}{l}\text { Other chronic obstructive pulmonary } \\
\text { disease }\end{array}$ & 0.6320 & $3.2 \%$ & 6.7 & $3.7 \%$ & $8(7-10.5)$ \\
\hline Pneumonia, organism unspecified & 0.6030 & $3.0 \%$ & 8.7 & $4.7 \%$ & $10(7-10.5)$ \\
\hline Inflammatory disease of prostate & 0.5911 & $3.0 \%$ & 12.2 & $6.6 \%$ & $10(10-16)^{1}$ \\
\hline Other & 7.9203 & $39.6 \%$ & 60.2 & $32.6 \%$ & $8(6-10.5)$ \\
\hline
\end{tabular}

IQR: interquartile range; LRTI: lower respiratory tract infection.

Broad-spectrum antibiotics included broad-spectrum penicillins (amoxicillin/clavulanic acid), macrolides, second and third generation cephalosporins and fluoroquinolones.

a $p<0.001$ compared with penicillins, after Bonferroni correction.

${ }^{b}$ p $<0.001$ compared with other beta-lactams excluding penicillins and cephalosporins, after Bonferroni correction.

c $p<0.001$ compared with cephalosporins and trimethoprim/sulfamethoxazole, after Bonferroni correction.

d $p<0.001$ compared with macrolides, after Bonferroni correction.

e $p<0.001$ compared with ciprofloxacin, after Bonferroni correction.

${ }^{f} p<0.001$ compared with ciprofloxacin and clarithromycin, after Bonferroni correction.

${ }^{\mathrm{g}} \mathrm{p}<0.001$ compared with cefprozil, cefuroxime, ciprofloxacin and clarithromycin, after Bonferroni correction.

${ }^{h} \mathrm{p}<0.001$ compared with all antiobiotics except for cefuroxime, after Bonferroni correction.

' $p$ < 0.001 compared with 'other dysfunction of urinary system', 'acute pharyngitis', 'cystistis', 'acute sinusitis' and 'inflammmatory disease of prostate', after Bonferroni correction.

i $p<0.001$ compared with all, except for cystitis, after Bonferroni correction.

$k p<0.001$ compared with all, except for acute pharyngitis, after Bonferroni correction.

I $p<0.001$ compared with all others, after Bonferroni correction.

${ }^{\mathrm{m}}$ Data are presented only for the most frequently prescribed antibiotics. 
respectively) in contrast to cefprozil and azithromycin that were prescribed for significantly shorter durations (Table 2).

\section{Antibiotic expenditures}

Throughout the whole study period, the total expenditures for antibiotics were EUR 184.6 million; EUR 66.5, 64.0 and 54.5 million during the first, second and third year of study respectively. Cephalosporins, macrolides and fluoroquinolones made up 93.1\% of the total antibiotic expenditures. Clarithromycin alone accounted for almost one quarter ( $24.5 \%$ or EUR 45.3 million) of the total antibiotic spending, followed by ciprofloxacin (15.2\% or EUR 28.1 million) and cefuroxime (11.7\% or EUR 21.7 million). Although amoxicillin/clavulanic acid was the fourth most frequently prescribed antibiotic, less than 3\% (EUR 5.1 million) of the total antibiotic expenditures were attributed it (Table 2).

\section{Antibiotic prescribing across selected clinical diagnoses}

The three most common clinical diagnoses for which antibiotics were prescribed in adult outpatients were, unspecified acute lower respiratory tract infections (LRTIS) (12.2\%), acute bronchitis (11.8\%) and other diseases of urinary system than cystitis (11.4\%), followed by acute pharyngitis (4.2\%) and cystitis (4.1\%). One third of all antibiotics (33.5\%) were prescribed for diagnoses for which antimicrobials are rarely or not indicated.

The most commonly prescribed antibiotics by clinical diagnosis are presented in Figure 2. Notably, clarithromycin was the most commonly prescribed antibiotic for unspecified acute LRTIs, acute bronchitis and for acute pharyngitis (33.2\%, $43.2 \%$ and $28.7 \%$, respectively). Ciprofloxacin was the most frequently prescribed antibiotic for cystitis and other diseases of the urinary system (20.7\% and $41.8 \%$, respectively) followed by norfloxacin $(22.5 \%$ and $20.4 \%$, respectively).

\section{Factors associated with broad-spectrum antibiotic prescribing}

Multivariate analysis revealed that adults older than 30 years were more likely to receive broad-spectrum antibiotics. In addition, pulmonologists and otorhinolaryngologists as well as physicians trained in eastern Europe (e.g. Bulgaria, Hungary or Romania) were more likely to prescribe broad-spectrum antibiotics compared with gynaecologists, urologists and doctors trained in Greece. However, physicians trained in these countries only contributed $5.5 \%$ of the overall prescribed antibiotics. Other diseases of the urinary system were associated with higher rates of broad-spectrum antibiotic prescribing compared with unspecified acute LRTIs, after adjustment for possible confounders. Furthermore, acute pharyngitis and other diagnoses were associated with lower rates of broad-spectrum antibiotic prescribing compared with unspecified acute LRTIs. Finally, broad-spectrum antibiotics were less likely to be prescribed for recurrent and chronic illnesses compared with first episode and acute diseases (Table 3).

\section{Discussion}

We aimed to assess the antibiotic prescription patterns in adult outpatients in Greece, as well as expenditures and potential factors associated with broad-spectrum antibiotic prescribing.

We found a high annual rate of antibiotic prescribing, but this seemed to decline over the studied period. The majority (89\%) of antibiotics prescribed were broadspectrum with a median duration of therapy of eight days. Almost one-third of all prescriptions were for ARTIs for which antibiotics are rarely or not indicated. The cost analysis revealed considerable healthcare expenditures for antibiotics.

The overall annual rate of 768 prescribed antibiotics per 1,000 adults that we found is much higher in comparison with countries such as Sweden (388 prescriptions/1,000 persons) [23], and similar to the United States (US) (833 prescriptions/1,000 persons) [24]. Perhaps the most alarming finding in our study was that $89 \%$ of all antibiotics prescribed were broadspectrum, with patientsolder than 60 years being the most common recipients ( $91.4 \%$ of antibiotic prescriptions). Shapiro et al. have recently reported high prescription rates of broad-spectrum antibiotics $(61 \%$ of total prescriptions) in the US, the majority of which (64\%) were given to patientsolder than 60 years [12]. In contrast, the most common antibiotics prescribed in Sweden were narrow-spectrum penicillins (30\% of total prescriptions) [23]. It is a well-known fact that in many cases, broad-spectrum antibiotics are prescribed instead of narrower-spectrum antibiotics, especially for the treatment of bacterial ARTIs $[9,11,23]$. In this context, the Hellenic Centre for Disease Control and Prevention has already taken initiatives to inform the public about the consequences of antibiotic misuse/ overuse and antimicrobial resistance and prepared instructions on the rational use of antibiotics [31].

Concerning the distribution of antibiotics, our study showed extensive use of macrolides, cephalosporins and fluoroquinolones, at higher percentages than in other countries. In the US, the top five list of prescribed antibiotics included azithromycin, amoxicillin, amoxicillin/clavulanic acid, ciprofloxacin and cefalexin in 2010 [24], which is similar to our results. In Switzerland, amoxicillin and amoxicillin/clavulanic acid were the most used antibiotics for outpatients, with fluoroquinolones and macrolides the second and third most prescribed antibiotics in 2007 [15]. In Germany most common antibiotics consumed were penicillin/ amoxicillin, followed by tetracyclines and newer macrolides (roxithromycin, azithromycin and clarithromycin) in 2003 [17]. It is unlikely that this variability in prescribing can be explained by differences in the epidemiology of ARTI. The rates of common ARTI are likely to be similar rather than different across countries in 


\section{TABLE 3A}

Differences in prescription of broad-spectrum antibiotics in adult outpatients, based on patient, physician and diagnosis characteristics, Greece, July 2010-June 2013

\begin{tabular}{|c|c|c|c|c|}
\hline & $\begin{array}{c}\text { Broad spectrum } \\
\text { (proportion of prescribed } \\
\text { antibiotics) }\end{array}$ & p value & $\begin{array}{l}\text { Crude OR } \\
(95 \% \mathrm{Cl})\end{array}$ & $\begin{array}{l}\text { Adjusted OR } \\
(95 \% \mathrm{Cl})\end{array}$ \\
\hline \multicolumn{5}{|l|}{ Patient characteristics } \\
\hline \multicolumn{2}{|l|}{ Age (years) } & $<0.001$ & & \\
\hline $20-29$ & $84.6 \%$ & & 1.00 & 1.00 \\
\hline $30-39$ & $87.8 \%^{a}$ & & $1.31(1.15-1.49)$ & $1.18(1.03-1.36)$ \\
\hline $40-49$ & $89.0 \%{ }^{a}$ & & $1.47(1.27-1.69)$ & $1.09(0.94-1.26)$ \\
\hline $50-59$ & $91.0 \% \%^{a, b}$ & & $1.84(1.57-2.15)$ & $1.17(0.99-1.39)$ \\
\hline$\geq 60$ & $91.4 \%{ }^{a, b}$ & & $1.93(1.69-2.20)$ & $1.12(0.97-1.31)$ \\
\hline \multicolumn{2}{|l|}{ Sex } & $<0.001$ & & \\
\hline Female & $87.4 \%$ & & 1.00 & - \\
\hline Male & $91.3 \%$ & & $1.52(1.38-1.67)$ & - \\
\hline \multicolumn{5}{|c|}{ Physician characteristics } \\
\hline \multicolumn{2}{|l|}{ Specialty } & $<0.001$ & & \\
\hline General practice & $93.1 \%$ & & 1.00 & 1.00 \\
\hline Pulmonology & $94.4 \%^{c}$ & & $1.25(1.04-1.50)$ & $1.47(1.21-1.79)$ \\
\hline Otorhinolaryngology & $95.4 \%^{c}$ & & $1.56(1.25-1.95)$ & $2.50(1.97-3.16)$ \\
\hline Gynaecology & $72.4 \%^{c, d, e}$ & & $0.20(0.17-0.22)$ & $0.21(0.18-0.24)$ \\
\hline Urology & $87.0 \% \%^{c, d, e}$ & & $0.50(0.43-0.58)$ & $0.62(0.52-0.74)$ \\
\hline Other & $79.1 \%{ }^{\text {c.d.e }}$ & & $0.28(0.24-0.33)$ & $0.36(0.31-0.43)$ \\
\hline \multicolumn{2}{|c|}{ Training location (self-identified) } & $<0.001$ & & \\
\hline Greece & $88.5 \%^{f}$ & & 1.00 & 1.00 \\
\hline Eastern Europe ${ }^{\mathrm{g}}$ & $92.9 \%$ & & $1.71(1.35-2.16)$ & $1.53(1.18-1.99)$ \\
\hline Western Europe ${ }^{\mathrm{h}}$ & $89.8 \%^{f}$ & & $1.14(1.02-1.28)$ & $0.81(0.71-0.94)$ \\
\hline \multicolumn{2}{|l|}{ Age } & $<0.001$ & & \\
\hline$<40$ & $90.7 \%{ }^{i}$ & & 1.00 & 1.00 \\
\hline $41-50$ & $90.7 \%{ }^{i}$ & & $1.00(0.82-1.22)$ & $1.07(0.86-1.33)$ \\
\hline $51-60$ & $88.7 \%^{i}$ & & $0.80(0.67-0.96)$ & $0.85(0.70-1.05)$ \\
\hline$\geq 60$ & $87.9 \%$ & & $0.74(0.62-0.90)$ & $0.78(0.64-0.97)$ \\
\hline \multicolumn{2}{|l|}{ Sex } & 0.979 & & \\
\hline Female & $89.0 \%$ & & 1.00 & - \\
\hline Male & $89.0 \%$ & & $0.99(0.86-1.15)$ & - \\
\hline
\end{tabular}

$\mathrm{Cl}$ : confidence interval; LRTI: lower respiratory tract infection; OR: odds ratio.

Statistically significant results are shown in bold.

a $p<0.001$ compared with age group 20-29 years, after Bonferroni correction.

${ }^{b} \mathrm{p}<0.001$ compared with age group 30-39 years, after Bonferroni correction.

c $p<0.001$ compared with general practice, after Bonferroni correction.

${ }^{d} p<0.001$ compared with pulmonology, after Bonferroni correction.

e $p<0.001$ compared with otolaryngology, after Bonferroni correction.

${ }^{\mathrm{f}} \mathrm{p}<0.001$ compared with group Eastern Europe, after Bonferroni correction.

$\mathrm{g}$ The tree most common countries were Bulgaria, Hungary and Romania. However, physicians trained in these countries only contributed $5.5 \%$ of the overall prescribed antibiotics.

h The tree most common countries were Germany, Italy and the United Kingdom.

i $p<0.001$ compared with age group $\geq 60$ years, after Bonferroni correction.

i $p<0.001$ compared with age group 41-50 years, after Bonferroni correction.

the European Union. Regarding resistance patterns, for pharyngitis, group A streptococci remain universally susceptible to penicillin.

Variations in the incidence of infections, educational and cultural background could be some of the reasons for the observed differences in antibiotic use between countries. Also, each country's treatment guidelines and pharmaceutical markets may influence doctors' prescribing behaviour $[25,26]$.

A comparison of our findings with the guidelines of the Hellenic Centre for Disease Control and Prevention for the ARTIs revealed that physicians in Greece seem to have partially adopted the national guidelines in terms of prescribed antibiotics and therapy duration. 
Differences in prescription of broad-spectrum antibiotics in adult outpatients, based on patient, physician and diagnosis characteristics, Greece, July 2010-June 2013

\begin{tabular}{|c|c|c|c|c|}
\hline & $\begin{array}{l}\text { Broad spectrum } \\
\text { (proportion of prescribed } \\
\text { antibiotics) }\end{array}$ & $\mathrm{p}$ value & $\begin{array}{l}\text { Crude OR } \\
(95 \% \mathrm{Cl})\end{array}$ & $\begin{array}{l}\text { Adjusted OR } \\
\quad(95 \% \mathrm{Cl})\end{array}$ \\
\hline \multicolumn{5}{|l|}{ Diagnosis related characteristics } \\
\hline \multicolumn{2}{|l|}{ Diagnosis } & $<0.001$ & & \\
\hline Unspecified acute LRTI & $96.0 \%$ & & 1.00 & 1.00 \\
\hline Acute bronchitis & $94.9 \%$ & & $0.76(0.58-1.02)$ & $0.82(0.62-1.08)$ \\
\hline $\begin{array}{l}\text { Other disease of the urinary system than } \\
\text { cystitis }\end{array}$ & $95.2 \%$ & & $0.81(0.61-1.07)$ & $1.51(1.12-2.02)$ \\
\hline Acute pharyngitis & $86.2 \%{ }^{k}$ & & $0.25(0.19-0.34)$ & $0.22(0.16-0.29)$ \\
\hline Cystitis & $87 \cdot 3 \%{ }^{\prime}$ & & $0.28(0.21-0.37)$ & $0.79(0.58-1.08)$ \\
\hline Other & $85.4 \%$ & & $0.24(0.19-0.29)$ & $0.48(0.38-0.61)$ \\
\hline \multicolumn{2}{|l|}{ Recurrence } & $<0.001$ & & \\
\hline First episode & $90.0 \%$ & & 1.00 & 1.00 \\
\hline Recurrence & $85.7 \%^{m}$ & & $0.67(0.60-0.75)$ & $0.76(0.64-0.90)$ \\
\hline Not specified & $87.9 \%{ }^{m}$ & & $0.81(0.72-0.91)$ & $1.10(0.96-1.27)$ \\
\hline \multicolumn{2}{|l|}{ Type of diagnosis } & $<0.001$ & & \\
\hline Acute & $90.3 \%$ & & 1.00 & 1.00 \\
\hline Chronic & $81.1 \%^{n}$ & & $0.46(0.41-0.52)$ & $0.62(0.52-0.74)$ \\
\hline Not specified & $84.9 \%^{n}$ & & $0.60(0.51-0.71)$ & $0.85(0.70-1.05)$ \\
\hline
\end{tabular}

$\mathrm{Cl}$ : confidence interval; LRTI: lower respiratory tract infection; OR: odds ratio.

Statistically significant results are shown in bold.

${ }^{k} p<0.001$ compared with all, except for cystitis and other, after Bonferroni correction.

${ }^{\prime} p<0.001$ compared with all, except for acute pharyngitis, after Bonferroni correction.

${ }^{m} \mathrm{p}<0.001$ compared with first episode, after Bonferroni correction.

${ }^{n} \mathrm{p}<0.001$ compared with acute diseases, after Bonferroni correction.

Specifically, we found that clarithromycin (i.e. macrolides) was the most commonly prescribed antibiotic for the treatment of acute pharyngitis, tonsillitis, LRTIs and chronic obstructive pulmonary disease, which is in agreement with national guidelines. On the other hand, it was noticeable that second generation cephalosporins such as cefprozil and cefuroxime were also commonly prescribed antibiotics for the management of acute pharyngitis, acute tonsillitis and LRTIs, although are not recommended by KEELPNO guidelines. With respect to treatment duration, our findings indicate that the median of therapy duration is close to that recommended by national guidelines for the vast majority of diagnoses.

We identified several factors that were related to broad-spectrum antibiotic prescribing. The strongest factors were patient's age over6o years, male sex and physician's specialty of pulmonology/otorhinolaryngology, which were additive. Factors associated with lower rates of broad-spectrum antibiotic choice included physician's training in Greece or western Europe compared with eastern Europe, older age of the physician, a diagnosis other than ARTI and a recurrent and/or chronic condition. There is no clear explanation for the fact that physicians who were trained in eastern Europe were more likely to prescribe broad-spectrum antibiotics.
However, we can hypothesise that the reason may be differences in medical education regarding antibiotic use, resistance and stewardship or differences in national policies and guidelines regarding antibiotic prescribing in these countries. It needs to be noted that this group constituted only a small sample of the total.

The total antibiotic expenditures for adult outpatients in Greece between 2010 and 2013 were approximately EUR 185 million, accounting for almost the $2 \%$ of the total public pharmaceutical expenditures in Greece during the study period. According to our study, one third of prescriptions were given for diagnoses that rarely or do not require antibiotic therapy, which means that approximately EUR 62 million could have been saved, no small sum considering the financial crisis that Greece has recently experienced.

Overall, our study indicated that antibiotic overprescribing is a problem in Greece. Patient pressure to prescribe them antibiotics and inadequate knowledge around appropriate utilisation of antibiotics are some of the factors leading to antibiotic overuse $[25,27]$.

Potential limitations of this study include the possibility that although doctors were randomly selected, our 
sample may not be representative of the total population of physicians. Second, patients in Greece can acquire antibiotics from pharmacists without a prescription [28]. The data from the Eurobarometer on antimicrobial resistance indicate that $15 \%$ of the Greek survey responders obtained their last course of antibiotics without prescription [29]. Third, we did not have access to prescribing data from hospitals and emergency departments, which could lead to an underestimation of the prescribing rates. Fourth, prescribing data may not accurately represent actual antibiotic consumption, since patient compliance with treatment is unknown. Fifth, direct assessment of appropriate antibiotic prescribing is difficult, as the IMS Health XPO database does not provide information on patient symptoms, severity of disease, drug allergies or whether or not a test was performed to identify bacteria or viruses. Sixth, the duration of antibiotic therapy was calculated indirectly by using available data on the number of prescribed packs, daily dose and dose frequency. As such, we cannot be sure that this was an accurate estimation of the actual treatment duration. Seventh, although it would be interesting to distinguish between different antibiotic classes within the broad-spectrum category and assess specific factors associated with them, the small sample size did not allow that. Finally, it should be noted that the costs related to antibiotic use throughout the whole study period may be underestimated as we used in our calculations the drug prices as published at the end of the year 2013 and it is known that there was a sharp reduction in drug prices in Greece during the period from 2010 to 2013.

\section{Conclusion}

We observed a high rate of antibiotic prescribing in adult outpatients in Greece, one-third of which were for diagnoses that rarely or do not require antibiotic therapy. Broad-spectrum antibiotics accounted for $89 \%$ of the total antibiotic prescriptions. The reasons for extensive use of broad-spectrum antibiotics need to be studied in depth. We have identified potential targets for antimicrobial stewardship including broadspectrum prescribing for most ARTIs as well as specific practitioner characteristics. Broad implementation of programmes targeting outpatient care settings should be a public health priority for Greece, with the final aim to reduce antimicrobial resistance and the financial burden.

\section{Conflict of interest}

None declared.

\section{Authors' contributions}

All authors contributed extensively to the work presented in this paper. All authors discussed the results and implications and commented on the manuscript at all stages. G.K designed the study. G.K and E.K carried out the statistical analysis of the data. E.G-K categorised the diagnoses and edited the manuscript. G.K, E.K and G.M wrote the manuscript. T.E.Z supervised the study and edited the manuscript.

\section{References}

1. Busfield J. Assessing the overuse of medicines.Soc Sci Med. 2015;131:199-206. DOI: 10.1016/j.socscimed.2014.10.061 PMID: 25464876

2. Courtenay M, Carter S, Rowbotham S, Peters S. Antibiotic prescribing in primary care: The need for interprofessional collaboration.J Interprof Care. 2015;29(4):404-5. DOI: 10.3109/13561820.2014.984020 PMID: 25514214

3. Arason VA, Sigurdsson JA, Erlendsdottir H, Gudmundsson $\mathrm{S}$, Kristinsson KG. The role of antimicrobial use in the epidemiology of resistant pneumococci: A 10-year follow up.Microb Drug Resist. 2006;12(3):169-76. DOI: 10.1089/ mdr.2006.12.169 PMID: 17002543

4. Bergman M, Huikko S, Huovinen P, Paakkari P, Seppälä H, Finnish Study Group for Antimicrobial Resistance (FiRe Network). Macrolide and azithromycin use are linked to increased macrolide resistance in Streptococcus pneumoniae. Antimicrob Agents Chemother. 2006;50(11):3646-50. DOI: 10.1128/AAC.00234-06 PMID: 16940064

5. Steinman MA, Gonzales R, Linder JA, Landefeld CS. Changing use of antibiotics in community-based outpatient practice, 1991-1999. Ann Intern Med. 2003;138(7):525-33. DOI: 10.7326/0003-4819-138-7-200304010-00008 PMID: 12667022

6. Costelloe C, Metcalfe C, Lovering A, Mant D, Hay AD. Effect of antibiotic prescribing in primary care on antimicrobial resistance in individual patients: systematic review and metaanalysis.BMJ. 2010;340(may18 2):c2096. DOI: 10.1136/bmj. C2096 PMID: 20483949

7. Ferech M, Coenen S, Malhotra-Kumar S, Dvorakova K, Hendrickx E, Suetens C, et al. European Surveillance of Antimicrobial Consumption (ESAC): outpatient antibiotic use in Europe. J Antimicrob Chemother. 2006;58(2):401-7. DOI: 10.1093/jac/dkl188 PMID: 16735414

8. John JF, Steed LL. Antibiotic resistance: a clinical danger beyond 2013.J S C Med Assoc. 2013;109(2):54-8.PMID: 24902392

9. Gill JM, Fleischut P, Haas S, Pellini B, Crawford A, Nash DB. Use of antibiotics for adult upper respiratory infections in outpatient settings: a national ambulatory network study. Fam Med. 2006;38(5):349-54.PMID: 16673197

10. Ladd $\mathrm{E}$. The use of antibiotics for viral upper respiratory tract infections: an analysis of nurse practitioner and physician prescribing practices in ambulatory care, 1997-2001.J Am Acad Nurse Pract. 2005;17(10):416-24. DOI: 10.1111/j.17457599.2005.00072.x PMID: 16181264

11. Steinman MA, Landefeld CS, Gonzales R. Predictors of broadspectrum antibiotic prescribing for acute respiratory tract infections in adult primary care.JAMA. 2003;289(6):719-25. DOI: 10.1001/jama.289.6.719 PMID: 12585950

12. Shapiro DJ, Hicks LA, Pavia AT, Hersh AL. Antibiotic prescribing for adults in ambulatory care in the USA, 2007-09.J Antimicrob Chemother. 2014;69(1):234-40. DOI: 10.1093/jac/dkt301 PMID: 23887867

13. Adriaenssens N, Coenen S, Versporten A, Muller A, Minalu G, Faes C, et al. European Surveillance of Antimicrobial Consumption (ESAC): outpatient antibiotic use in Europe (19972009). J Antimicrob Chemother. 2011;66(Suppl 6):vi3-12.PMID: 22096064

14. European Centre for Disease Prevention and Control (ECDC). Antimicrobial resistance surveillance in Europe 2012. Stockholm: ECDC; 2013. Available from: http://ecdc.europa. eu/en/publications/Publications/antimicrobial-resistancesurveillance-europe-2012.pdf

15. Achermann R, Suter K, Kronenberg A, Gyger P, Mühlemann $\mathrm{K}$, Zimmerli W, et al. Antibiotic use in adult outpatients in Switzerland in relation to regions, seasonality and point of care tests. Clin Microbiol Infect. 2011;17(6):855-61. DOI: 10.1111/j.1469-0691.2010.03348.x PMID: 20731682

16. Haeseker MB, Dukers-Muijrers NH, Hoebe CJ, Bruggeman CA, Cals JW, Verbon A. Trends in antibiotic prescribing in adults in Dutch general practice.PLoS One. 2012;7(12):e51860. DOI: 10.1371/journal.pone.0051860 PMID: 23251643

17. Kern WV, de With K, Nink K, Steib-Bauert M, Schröder H. Regional variation in outpatient antibiotic prescribing in Germany.Infection. 2006;34(5):269-73. DOI: 10.1007/S15010006-6618-y PMID: 17033751

18. Malo S, José Rabanaque M, Feja C, Jesús Lallana M, Aguilar I, Bjerrum L. High antibiotic consumption: a characterization of heavy users in Spain.Basic Clin Pharmacol Toxicol. 2014;115(3):231-6. DOI: 10.1111/bcpt.12211 PMID: 24517562 
19. Masiero G, Filippini M, Ferech M, Goossens H. Socioeconomic determinants of outpatient antibiotic use in Europe.Int J Public Health. 2010;55(5):469-78. DOI: 10.1007/s00038-010-0167-y PMID: 20603713

20. Pan A, Buttazzi R, Marchi M, Gagliotti C, Resi D, Moro ML, Antibiotic Use and Resistance Surveillance Study Group of Regione Emilia-Romagna. Secular trends in antibiotic consumption in the adult population in Emilia-Romagna, Italy, 2003-2009.Clin Microbiol Infect. 2011;17(11):1698-703. DOI: 10.1111/j.1469-0691.2011.03500.x PMID: 21595784

21. Zhang Y, Lee BY, Donohue JM. Ambulatory antibiotic use and prescription drug coverage in older adults. Arch Intern Med. 2010;170(15):1308-14. DOI: 10.1001/archinternmed.2010.235 PMID: 20696953

22. Chahwakilian P, Huttner B, Schlemmer B, Harbarth S. Impact of the French campaign to reduce inappropriate ambulatory antibiotic use on the prescription and consultation rates for respiratory tract infections.J Antimicrob Chemother. 2011;66(12):2872-9. DOI: 10.1093/jac/dkr387 PMID: 21965428

23. Ternhag A, Hellman J. More on U.S. outpatient antibiotic prescribing, 2010.N Engl J Med. 2013;369(12):1175-6. DOI: 10.1056/NEJMC1306863 PMID: 24047078

24. Hicks LA, Taylor TH, Hunkler RJ. U.S. outpatient antibiotic prescribing, 2010.N Engl J Med. 2013;368(15):1461-2. DOI: 10.1056/NEJMC1212055 PMID: 23574140

25. Butler CC, Simpson SA, Dunstan F, Rollnick S, Cohen D, Gillespie D, et al. Effectiveness of multifaceted educational programme to reduce antibiotic dispensing in primary care: practice based randomised controlled trial. BMJ. 2012;344(febo2 1):d8173. DOI: 10.1136/bmj.d8173 PMID: 22302780

26. Laat E, Windmeijer F, Douwer R. How does pharmaceutical marketing influence doctors' prescribing behaviour? The Hague: CPB Netherlands' Bureau for Economic Policy Analysis; 2002. Available from: http://www.cpb.nl/sites/default/files/ publicaties/download/how-does-pharmaceutical-marketinginfluence-doctors-prescribing-behaviour.pdf

27. Plachouras D, Antoniadou A, Giannitsioti E, Galani L, Katsarolis I, Kavatha D, et al. Promoting prudent use of antibiotics: the experience from a multifaceted regional campaign in Greece. BMC Public Health. 2014;14(1):866. DOI: 10.1186/1471-2458-14866 PMID: 25149626

28. Plachouras D, Kavatha D, Antoniadou A, Giannitsioti E, Poulakou G, Kanellakopoulou K, et al. Dispensing of antibiotics without prescription in Greece, 2008: another link in the antibiotic resistance chain. Euro Surveill. 2010;15(7):19488.PMID: 20184852

29. Special Eurobarometer 407. Antimicrobial resistance. Brussels European Commission; 2013. Available from: http://ec.europa. eu/health/antimicrobial_resistance/docs/ebs_407_en.pdf

30. Demographic and social characteristics of the resident population of Greece according to the 2011 population-housing census revision of 20/3/2014. Piraeus: Hellenic Statistical Authority; 2014. Available from: http://www.statistics.gr/en/ statistics/-/publication/SAMo3/-

31. Audiovisual material. Thessaloniki: Hellenic Center for Disease Control and Prevention. [Accessed: 8 Aug 2015].

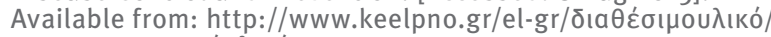

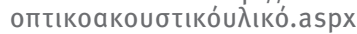

